\title{
Effect of Passive Ultrasonic Irrigation on Apical Extrusion of Irrigating Solution
}

\author{
Tamer Tasdemir \\ Kursat Era \\ Davut Celik ${ }^{a}$ \\ Tahsin Yildirim ${ }^{b}$
}

\section{ABSTRACT}

Objectives: To determine the influence of passive ultrasonic irrigation (PUI) on apical extrusion of irrigating solution.

Methods: Twenty freshly extracted maxillary and mandibular incisors with single straight root canals were instrumented with ProTaper rotary files. During final irrigation, the root canals were filled with $2.5 \%$ sodium hypochlorite $(\mathrm{NaOCl})$ solution and PUI was performed with a piezoelectronic unit. A stainless steel instrument (size 15) was inserted into the root canal and the irrigant was ultrasonically activated for one minute. This sequence was repeated three times, resulting in a total PUI time of three minutes. The volume of extruded irrigant was measured by Pipetman pipettes. The data were statistically analyzed with the Mann-Whitney $U$ test.

Results: The mean volume of apical extruded irrigant was $2.15 \mu \mathrm{L}$ for the PUI group and $14 \mu \mathrm{L}$ for the control group. The experimental group extruded significantly smaller amounts of irrigant than the control group $(\mathrm{P}<.05)$.

Conclusions: The PUI procedure as a final irrigation was associated with less apical extrusion of the irrigating solution. (Eur J Dent 2008;2:198-203)

Key words: Apical extrusion; Passive; Ultrasonic; Irrigation.

\section{INTRODUCTION}

Root canal irrigation plays an important role in the debridement and disinfection of the root canal system. ${ }^{1}$ The currently available evidence strongly favors $\mathrm{NaOCl}$ as the main endodontic

a Department of Endodontics, School of Dentistry, Karadeniz Technical University, Trabzon, Turkey.

b Department of Restorative Dentistry, School of Dentistry, Karadeniz Technical University,

Trabzon, Turkey.

Corresponding author: Dr. Kursat Er, Department of Endodontics, School of Dentistry, Karadeniz Technical University, 61080, Trabzon, Turkey. Phone: +904623774735

Fax: +904623253017

E-mail: kursateraktu.edu.tr irrigant. $^{2}$ Several investigations have shown its antibacterial effectiveness and tissue dissolution capacity. ${ }^{3-5}$ However, $\mathrm{NaOCl}$ is tissue cytotoxic and, when it contacts vital tissues; it causes hemolysis and ulceration, inhibits neutrophile migration and damages endothelium and fibroblast cells. ${ }^{6}$ Current dental literature includes many case presentations that report the damage to periapical tissues caused by $\mathrm{NaOCl}$ extruded accidentally from the apical foramen. ${ }^{1,7-9}$ Therefore, the possibility of accidental extrusion of $\mathrm{NaOCl}$ solution beyond the apical constriction must be considered during root canal irrigation.

The first use of ultrasonics in endodontic practice was described by Richman ${ }^{10}$. Martin 
et $\mathrm{al}^{11}$ demonstrated ultrasonically activated $\mathrm{K}$ files' ability to cut dentin. However, the results of studies evaluating root canal preparations carried out with ultrasonic devices differ considerably. Several studies have reported that the use of oscillating instrumentation, with ultrasonically powered devices, are superior to conventional enlarging methods for preparing root canals and/ or eliminating debris. ${ }^{12-14}$ In contrast, Cymerman et $\mathrm{al}^{15}$ reported no significant difference between hand and ultrasonic instrumentation. Other studies found hand instrumentation to be superior to ultrasonic technique. ${ }^{16-19}$ Ahmad et $\mathrm{al}^{20,21}$ reported that ultrasonically activated devices bend inside the canal or contact the canal's walls, restricting their own vibration and cleaning activities.

This uncontrolled action of the file during ultrasonic preparation is the reason that ultrasonics is not routinely used for shaping. ${ }^{22}$ However, it has been shown that ultrasonically driven files are effective for the "irrigation" of root canals. ${ }^{21}$ Therefore, the use of ultrasonics in canals has evolved from primary instrumentation to a passive cleaning technique. PUI was first described by Weller et al, ${ }^{23}$ and "passive activation" in this technique means that the instrument inside the canal does not contact the canal's walls. During PUI, a small file or smooth wire (e.g., size 15) that is placed at the center of the root canal after shaping the canal, and when this file or wire is activated ultrasonically, "acoustic streaming" occurs. ${ }^{21}$ Acoustic streaming creates small, intense, circular fluid movement li.e., eddy flow) around the instruments. The eddying occurs closer to the tip than in the coronal end of the file, with an apically directed flow at the tip. $^{24}$ Because the root canal is enlarged, the file or wire can vibrate freely in a way to enable acoustic streaming, and it transfers its energy to the irrigant inside the canal. ${ }^{21}$ This acoustic streaming, which is created by the instrument passively activated with ultrasonic energy, increases the cleaning effect of the irrigant inside the canal by means of hydrodynamic cutting power. ${ }^{25}$ Various studies have shown that $\mathrm{NaOCl}$ used with PUI removes more dentin debris, planktonic bacteria and pulp tissue from the root canal than syringe irrigation. ${ }^{26-28}$ An increase in the temperature of the irrigant may be a reason to include ultrasonic devices in canal irrigation; these devices also increase the tissue-dissolving capabilities of $\mathrm{NaOCl}$ solution. ${ }^{24}$

Recently, with its gradually increasing popularity, passive ultrasonic activation of endodontic instruments has been suggested as a means to improve canal debridement, ${ }^{29,30}$ canal disinfection ${ }^{31,32}$ and canal sealing. ${ }^{33}$ PUI also has been recommended for removing $\mathrm{Ca}(\mathrm{OH})_{2}$ from the root canal. ${ }^{34,35}$ However, whether PUI as an effective irrigation method causes extrusion of irrigant from the apical foramen remains unknown. The purpose of the present study was to evaluate in vitro the amount of irrigant extruded apically from extracted teeth during PUI using $2.5 \% \mathrm{NaOCl}$ solution.

\section{MATERIALS AND METHODS}

Specimen preparation

Twenty extracted human single rooted maxillary and mandibular incisors with mature apices were used in this study. They had straight root canals of similar size to reduce effects of canal size and curvature on the extrusion of irrigant. Radiographic images from the buccal and proximal aspects of each sample were exposed. Teeth with extremely large canals and open apex in the radiographic images were excluded from the study. After hard and soft tissue remnants were cleaned, the teeth were kept in a $10 \%$ formalin solution before use.

Standard access preparation was accomplished using high-speed diamonds and water spray. A size $10 \mathrm{~K}$ file IVDW Antaeos, Munich, Germanyl was placed into the canal until it was visible at the apical foramen. The working length (WL) was established $1 \mathrm{~mm}$ short of this length. Each root canal's apical dimension was determined in accordance with the size of the biggest file that closely contacted the canal's walls in WL without applying any force. Only root canals with an apical diameter from sizes 15-20 were used. The teeth were decoronated in order to obtain root segments approximately $14 \mathrm{~mm}$ long.

Instrumentation and collection of extruded irrigant

Each canal's coronal aspect was flared using Gates Glidden drills sizes 2-4 (Dentsply Maillefer, 
Ballaigues, Switzerland). The remaining canal space was shaped in a crown-down manner with ProTaper instruments (Dentsply Maillefer), and apical instrumentation at WL was completed with an F3 file (ISO size 30, taper 0.09-0.05). Between the instruments, each canal was irrigated with 2 $\mathrm{mL}$ of a $2.5 \% \mathrm{NaOCl}$ solution using a syringe and a 27-gauge needle. Apical patency was checked with a size $10 \mathrm{~K}$-file between each instrument.

After preparing the root canal, the method that Myers and Montgomery ${ }^{36}$ recommended was used to determine the amount of solution extruding from the apical foramen during the PUI as a final irrigation. Each sample was attached to a rubber stopper, and root apexes that would fit into a $4 \mathrm{~mL}$ centrifuge tube were placed into a glass bottle together with the tube. In order to equalize the air pressure in and outside the bottle, a 23-gauge needle was inserted into the bottle through the rubber stopper (Figure 1).

Group 1 (control group): The canal was filled with $2.5 \%$ solution of $\mathrm{NaOCl}$ using a syringe and a 30-gauge irrigation needle with a side opening and a rounded tip (KerrHawe SA, Bioggio, Switzerland) which penetrated to within 1 to 2 $\mathrm{mm}$ from the working length.. After one minute, if there was extrusion from the apical foramen and the amount of irrigant in the canal was reduced, the canal was refilled with irrigant. This sequence was repeated three times resulting in a total irrigation time of three minutes. At the end of this period, each tooth was removed from the centrifuge tube and the centrifuge tube was removed from the vial. The volume of extruded irrigant was measured by Pipetman pipettes (Gilson, Inc., Middleton, WI, USA).

Group 2 (experimental group): The same teeth used in Group 1 were also used in group 2 after their canals were completely dried with absorbent paper points. After the root canal was filled with $2.5 \% \mathrm{NaOCl}$ solution, using the same syringe and irrigation needle used for the control group, PUI was performed with a piezoelectrical ultrasonic unit (NSK Varios 750, Nakanishi, Tochigi, Japan). A stainless steel instrument (size 15) (Varios U files) was inserted into the root canal $1 \mathrm{~mm}$ short of the WL, and the irrigant was ultrasonically activated for one minute. After the reduced amount of irrigant was supplemented, the irrigant was reactivated ultrasonically for another minute. This sequence was repeated three times, resulting in a total PUI time of three minutes. The volume of extruded irrigant was measured as mentioned for the control group.

The data were statistically analyzed with the Mann-Whitney $U$ test, and $P$ was set at .05.

\section{RESULTS}

Table 1 presents the mean volume and standard deviations of irrigant extruded for each group, and the range of volume extruded (minimum and maximum values). The mean volume of apical extruded irrigant was $2.15 \pm 2.73$ $\mu \mathrm{L}$ for the PUI group and $14 \pm 13.03 \mu \mathrm{L}$ for the control group. The experimental group extruded significantly less irrigant than the control group $(P<.05)$.

\section{DISCUSSION}

A method different from the routine clinical practice was applied in this in vitro study. That is, in a clinical setting, the root canal is generally

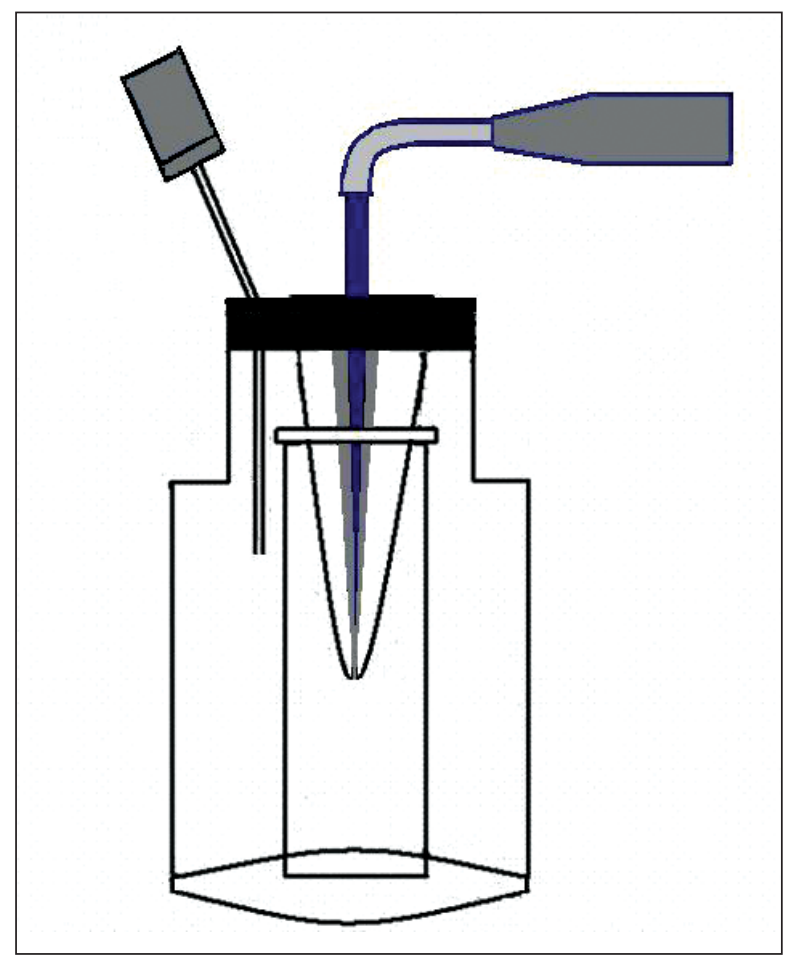

Figure 1. Irrigant extruded through the apical foramen was collected in a centrifuge tube.

Table 1. The mean volume of extruded irrigant $(\mu \mathrm{L})$.

\begin{tabular}{|c|c|c|c|c|}
\hline & $\mathrm{n}$ & Minimum & Maximum & Mean $\pm S D$ \\
\hline Control & 20 & 0 & 35.0 & $14.00 \pm 13.03$ \\
\hline PUI & 20 & 0 & 8.0 & $2.15 \pm 2.73$ \\
\hline
\end{tabular}


irrigated with $2 \mathrm{~mL} \mathrm{NaOCl}$ solution using a syringe and irrigation needle, PUI is applied for 30 seconds or one minute, and the root canal is again irrigated in the same manner. This procedure is repeated several times. A second option is to enable a continuous flow of irrigation during PUI. The results of a previous study showed no significant difference between syringe delivery of the irrigant and a continuous flow of irrigant when PUI was used for three minutes. ${ }^{37}$ This study's aim was to determine the volume of apically extruded solution only during PUI procedure. Therefore, in order to eliminate the amount of solution possibly extruded during push pressure with the syringe, the root canal was only filled with irrigation solution in each group, and the amount of solution extruded from the apical foramen for three minutes was measured with a pipette. The same canals were used in both groups to eliminate the variables encountered in root canals in different teeth, such as curvature and canal diameter.

Previous study reported that ultrasonic irrigation was more effective in removing artificially placed dentine debris from simulated canal extensions from canals with greater tapers. ${ }^{38}$ This study obtained canals with greater tapers by using Gates Glidden burs and ProTaper instruments. Maximum attention was paid to avoid the instruments' contact the canal's walls during PUI procedure. The $\mathrm{NaOCl}$ solution's to be not extruded through the apical foramen or pushed to the less level during PUI may be explained by the effect of acoustic streaming inside the canal, which can move the solution inside the canal from the apical toward the coronal direction. Moreover, the decoronated teeth do not provide a coronal reservoir for the irrigation solution. When activating the intracanal solution using ultrasonic a considerable amount of solution may be lost coronally, decreasing the hydrostatic pressure towards the apex.

The objective of this study was to assess the apical extrusion of $2.5 \% \mathrm{NaOCl}$ solution during PUI. According to the data obtained in the study, the amount of apically extruded irrigant during PUI is fairly little.

It must be emphasized that the results of this study should not be directly extrapolated to the clinical situation. No attempt has been made to simulate the presence of vital pulp or periapical tissues, an in vivo model may give different result, as the periapical tissues may serve as a natural barrier, inhibiting debris extrusion. Results may also differ because of positive or negative pressure at the apex and with normal or pathological tissues. Furthermore, this study was limited to teeth with mature root morphology. The observed results should not be generalized to teeth with immature root development and open apicies.

PUl's cleaning efficacy implies the effective removal of dentine debris, microorganisms (planktonic or in biofilm) and organic tissue from the root canal. Acoustic streaming the irrigant enhances its potential to contact a large surface area of the canal's wall. ${ }^{39}$ Besides these positive attributes, the fact that PUI, as the final irrigation, does not push the $\mathrm{NaOCl}$ solution to periapical tissues may enable it to become a critical component of modern endodontic therapy.

\section{CONCLUSIONS}

When a file is passively activated in a canal by ultrasonics for three minutes after instrumentation, it results low risks of apical extrusion of the irrigating solution.

\section{REFERENCES}

1. Hülsmann M, Hahn W. Complications during root canal irrigation-literature review and case reports. Int Endod $J$ 2000;33:186-193.

2. Zehnder M. Root canal irrigants. J Endod 2006;32:389-398.

3. Zehnder M, Kosicki D, Luder H, Sener B, Waltimo T. Tissuedissolving capacity and antibacterial effect of buffered and unbuffered hypochlorite solutions. Oral Surg Oral Med Oral Pathol Oral Radiol Endod 2002;94:756-762.

4. Naenni N, Thoma K, Zehnder M. Soft tissue dissolution capacity of currently used and potential endodontic irrigants. J Endod 2004;30:785-787.

5. Sirtes G, Waltimo T, Schaetzle M, Zehnder M. The effects of temperature on sodium hypochlorite short-term stability, pulp dissolution capacity, and antimicrobial efficacy. $J$ Endod 2005;31:669-671

6. Gatot A, Arbelle J, Leiberman A, Yanai-Inbar I. Effects of sodium hypochlorite on soft tissues after its inadvertent injection beyond the root apex. J Endod 1991;17:573-574.

7. Gernhardt CR, Eppendorf K, Kozlowski A, Brandt M. Toxicity of concentrated sodium hypochlorite used as an endodontic irrigant. Int Endod J 2004;37:272-280. 
8. Witton R, Henthorn K, Ethunandan M, Harmer S, Brennan PA. Neurological complications following extrusion of sodium hypochlorite solution during root canal treatment. Int Endod $J$ 2005;38:843-848.

9. Bowden JR, Ethunandan M, Brennan PA. Life-threatening airway obstruction secondary to hypochlorite extrusion during root canal treatment. Oral Surg Oral Med Oral Pathol Oral Radiol Endod 2006;101:402-404.

10. Richman MJ. The use of ultrasonics in root canal therapy and root resection. $J$ Dental Med 1957;12:12-18.

11. Martin H, Cunningham WT, Norris JP, Cotton WR. Ultrasonic versus hand filing of dentin: a quantitative study. Oral Surg Oral Med Oral Pathol 1980;49:79-81.

12. Kielt LW, Montgomery S. The effect of endosonic instrumentation in simulated curved root canals. $J$ Endod 1987; 13:215-219.

13. Stamos DE, Sadeghi EM, Haasch GC, Gerstein H. An in vitro comparison study to quantitate the debridement ability of hand, sonic, and ultrasonic instrumentation. $J$ Endod 1987;13:434-440

14. Yamaguchi M, Matsumori M, Ishikawa $H$, Sakurai $T$, Nakamura H, Naitoh M, Shiojima M, Kikuchi A. The use of ultrasonic instrumentation in the cleansing and enlargement of the root canal. Oral Surg Oral Med Oral Pathol 1988;65:349-353.

15. Cymerman JJ, Jerome LA, Moodnik RM. A scanning electron microscope study comparing the efficacy of hand instrumentation with ultrasonic instrumentation of the root canal. J Endod 1983;9:327-331.

16. Cunningham WT, Martin H, Pelleu GB Jr, Stoops DE. A comparison of antimicrobial effectiveness of endosonic and hand root canal therapy. Oral Surg Oral Med Oral Pathol 1982;54:238-241.

17. Cunningham WT, Martin H, Forrest WR. Evaluation of root canal débridement by the endosonic ultrasonic synergistic system. Oral Surg Oral Med Oral Pathol 1982;53:401-404.

18. Cunningham WT, Martin H. A scanning electron microscope evaluation of root canal debridement with the endosonic ultrasonic synergistic system. Oral Surg Oral Med Oral Pathol 1982;53:527-531

19. Loushine RJ, Weller RN, Hartwell GR. Stereomicroscopic evaluation of canal shape following hand, sonic, and ultrasonic instrumentation. J Endod 1989;15:417-421.

20. Ahmad M, Pitt Ford TR, Crum LA. Ultrasonic debridement of root canals: an insight into the mechanisms involved. $J$ Endod 1987;13:93-101.

21. Ahmad M, Pitt Ford TJ, Crum LA. Ultrasonic debridement of root canals: acoustic streaming and its possible role. $J$ Endod 1987; 13:490-499.
22. van der Sluis LWM, Wu M-K, Wesselink PR. A comparison between a smooth wire and a K-file in removing artificially placed dentine debris from root canals in resin blocks during ultrasonic irrigation. Int Endod J 2005;38:593-596.

23. Weller RN, Brady JM, Bernier WE. Efficacy of ultrasonic cleaning. J Endod 1980;6:740-743.

24. Himel VT, McSpadden J, Goodis HE. Instrument, materials and devices. In: Cohen S, Hargreves K, Keiser K. Pathways of the Pulp, 9th ed. St. Louis: Mosby, 2006, pp. 233- 289.

25. Jensen SA, Walker TL, Hutter JW, Nicoll BK. Comparison of the cleaning efficacy of passive sonic activation and passive ultrasonic activation after hand instrumentation in molar root canals. J Endod 1999;25:735-738.

26. Huque J, Kota K, Yamaga M, Iwaku M, Hoshino E. Bacterial eradication from root dentine by ultrasonic irrigation with sodium hypochlorite. Int Endod $J$ 1998;31:242-250.

27. Lee S-J, Wu M-K, Wesselink PR. The effectiveness of syringe irrigation and ultrasonics to remove debris from simulated irregularities within prepared root canal walls. Int Endod J 2004;37:672-678.

28. Gutarts R, Nusstein J, Reader A, Beck M. In vivo debridement efficacy of ultrasonic irrigation following hand rotary instrumentation in human mandibular molars. J Endod 2005;31:166-170.

29. Plotino G, Pameijer CH, Grande NM, Somma F. Ultrasonics in endodontics: a review of the literature. $J$ Endod 2007;33:81-95.

30. Munley PJ, Goodell GG. Comparison of passive ultrasonic debridement between fluted and nonfluted instruments in root canals. J Endod 2007;33:578-580.

31. Spoleti P, Siragusa M, Spoleti MJ. Bacteriological evaluation of passive ultrasonic activation. J Endod 2003;29:12-14.

32. Carver K, Nusstein J, Reader A, Beck M. In vivo antibacterial efficacy of ultrasound after hand and rotary instrumentation in human mandibular molars. J Endod 2007;33:1038-1043.

33. van der Sluis LWM, Shemesh H, Wu MK, Wesselink PR. An evaluation of the influence of passive ultrasonic irrigation on the seal of root canal fillings. Int Endod $J$ 2007;40:356361.

34. Kenee DM, Allemang JD, Johnson JD, Hellstein J, Nichol BK. A quantitative assessment of efficacy of various calcium hydroxide removal techniques. J Endod 2006;32: 563-565.

35. van der Sluis LWM, Wu MK, Wesselink PR. The evaluation of removal of calcium hydroxide paste from an artificial standardized groove in the apical root canal using different irrigation methodologies. Int Endod J 2007;40:52-57.

36. Myers GL, Montgomery S. A comparison of weights of debris extruded apically by conventional filing and Canal Master techniques. J Endod 1991;17:275-279. 
37. van der Sluis LWM, Gambarini G, Wu MK, Wesselink PR. The influence of volume, type of irrigant and flushing method on removing artificially placed dentine debris from the apical root canal during passive ultrasonic irrigation. Int Endod J 2006;39:472-476.

38. van der Sluis LWM, Wu M-K, Wesselink PR. The efficacy of ultrasonic irrigation to remove artificially placed dentine debris from human root canals prepared using instruments of varying taper. Int Endod $J$ 2005;38:764-768.

39. van der Sluis LWM, Versluis M, Wu MK, Wesselink PR. Passive ultrasonic irrigation of the root canal: a review of the literature. Int Endod J 2007;40:415-426. 